\title{
Dual rolls equal channel extrusion as unconventional SPD process of the ultralow-carbon steel: finite element simulation, experimental investigations and microstructural analysis
}

\author{
M. B. Jabłońska ${ }^{1}$ (D) $\cdot$ K. Kowalczyk ${ }^{1} \cdot$ M. Tkocz ${ }^{1} \cdot$ T. Bulzak $^{2} \cdot$ I. Bednarczyk ${ }^{1} \cdot$ S. Rusz ${ }^{3}$
}

Received: 15 November 2020 / Revised: 10 December 2020 / Accepted: 12 December 2020 / Published online: 7 February 2021

(c) The Author(s) 2021

\begin{abstract}
The paper presents results of FEM modelling as well as properties and microstructure of the ultralow-carbon ferritic steel after the unconventional SPD process-DRECE (dual rolls equal channel extrusion). Based on the conducted numerical simulation information about the deformation behaviour of a steel strip during the DRECE process was obtained. The simulation results were experimentally verified. The influence of DRECE process on hardness distribution, fracture behaviour and microstructure evolution of the investigated steel was analysed. The increase of steel strength properties after subsequent deformation passes was confirmed. The microstructural investigations revealed that the processed strips exhibit the dislocation cell microstructure and subgrains with mostly low-angle grain boundaries. The grains after processing had relatively high dislocation density and intense microband formation was observed. It was also proved that this unconventional SPD method fosters high grain refinement.
\end{abstract}

Keywords SPD process $\cdot$ Finite element analysis $\cdot$ Ultralow-carbon steel $\cdot$ Mechanical properties $\cdot$ Microstructure

\section{Introduction}

The concept of creating materials with highly fragmented microstructure is very relevant. The increasing requirements, which modern materials need to meet, have enforced improvement of manufacturing processes to obtain high mechanical properties [1,2]. The most common methods of producing materials with nano-grained and ultrafine-grained microstructure are the SPD (Severe Plastic Deformation) methods. SPD processes are defined as metal forming processes during which the accumulation of strain causes refining of the microstructure while maintaining the cohesion of the deformed material [1-4].

M. B. Jabłońska

magdalenabarbara.jablonskapriv@gmail.com

1 Faculty of Materials Engineering, Silesian University of Technology, Krasińskiego 8, 40-019 Katowice, Poland

2 Faculty of Mechanical Engineering, Lublin University of Technology, Nadbystrzycka 36, 20-618 Lublin, Poland

3 Faculty of Mechanical Engineering, VSB, Technical University of Ostrava, 17. Listopadu 2172/15,

Ostrava-Poruba 708 00, Czech Republic
The best-known SPD methods are equal channel angular pressing (ECAP) [5, 6], cyclic extrusion compression (CEC) [7], high-pressure torsion (HPT) [8], accumulative roll bonding (ARB) [9], KOBO extrusion and hydrostatic extrusion $[10,11]$. However, due to the low efficiency of SPD processes, the ability to deform only small samples as well as unsatisfactory homogeneity of obtained microstructure, several attempts to combine different SPD methods were made in recent years. The unconventional methods of severe plastic deformation and hybrid techniques significantly increase the grain refinement and allow to increase the process efficiency and reduce material losses at the same time [12-19]. These methods include among others: hydrostatic tube cyclic expansion extrusion (HTCEE), repetitive forging (RF), asymmetrical accumulative roll bonding (AARB), CONFORM extrusion and dual rolls equal channel extrusion (DRECE). Until now both kinds of methods: conventional and nonconventional including hybrid techniques were used to form the properties as well as the grain refinement of non-ferrous alloys (aluminium and copper alloys especially) [12-15]. The DRECE method also originally was used for the non-ferrous alloys [16, 17]. This unconventional method uses the principle of repetitive passes 
between the same set of dies to refine the microstructure and improve the strength properties of a metal strip. The forming process is based on the extrusion technology without the reduction of strip thickness while achieving high accumulated effective strain in the material being formed. In comparison to most other, the DRECE method, due to its main advantage, i.e. the possibility of forming large-section strips, has been used in recent years to form the steel strips with positive results $[18,19]$. However, the research results in this area mainly concern on the influence of DRECE parameters on properties of selected steels. Numerical simulations on the behaviour of the steels during the DRECE deformation have not been performed so far.

The finite element method is currently a standard for solving many engineering problems. It is also intensively used to understand the effects occurring during various SPD processes. Knowledge of deformation behaviour, as well as strain and stress distributions in a processed workpiece, is necessary to understand the relationships between process parameters (e.g. geometric features of dies) [20-23], microstructure evolution and resulting functional properties of a finished product [24-30]. Most of the reported FEM analyses concerns the classical ECAP process issues, including an effect of the channel angle and the outer die angle on material deformation behaviour [22-24], analysis of the deformation distribution which indicates that it is not homogeneous [25-27], and heterogeneity of the obtained refinement of the microstructure [28-30]. However, in the subject literature, there are very few studies based on numerical simulations of unconventional and hybrid SPD processes including DRECE. The paper presents results of a DRECE process FEM numerical modelling. The simulation results were combined with the corresponding experimental results to analyse the effect of repetitive deformation by the DRECE method on the microstructure and properties of the low-carbon steel. The application potential of this severe plastic deformation method to improve the steel properties by grain refinement is discussed.

\section{Research methodology}

The testing material had a form of 800-mm-long, 60-mmwide and 2-mm-thick strips made of the interstitial-free ultralow-carbon steel. The chemical composition of steel was as follows (wt $\%$ ): $0.003 \% \mathrm{C}, 0.005 \% \mathrm{Si}, 0.17 \% \mathrm{Mn}$, $0.029 \% \mathrm{Al}, 0.0027 \% \mathrm{~N}, 0.073 \% \mathrm{Ti}$. The as-received material was after cold rolling and subsequent annealing at the temperature of $850{ }^{\circ} \mathrm{C}$ with the holding time of $25 \mathrm{~min}$. As a result of this treatment, the homogenous ferritic microstructure with the average grain diameter of ca. $45 \mu \mathrm{m}$ was obtained (Fig. 1).

The finite element numerical modelling of the DRECE process was performed in the Simufact Forming ver. 15.0 software. The process was simulated in the spatial states of strain and stress; thus, 3D geometric models of the DRECE device and the steel strip were created in the Solid Edge ST9 CAD software (Fig. 2). Tools, i.e. the main roll, the supporting tool, two backing (feed) rolls, the upper and lower die supports as well as the upper and lower dies were considered as fixed objects while the steel strip was modelled as the elastic-plastic one. The channel angle, namely the angle at which the inlet channel (between the upper die and the main roll) intersects with the outlet channel (between the lower and upper dies). The channel angle is one of the principal parameters of the DRECE process and has a significant effect on the material flow and the resulting microstructure. The channel angle of $108^{\circ}$ was selected in this simulation case, based on the previous studies on this issue, reported in [29].

For digitalization of the steel strip, surface elements were used (a sheet mesh type with the average size of $1 \mathrm{~mm}$ ). The conducted numerical simulation was purely mechanical, which means that no changes in thermal parameters were analysed during the numerical simulations. The contact conditions between the tools and the steel strip were described by the Coulomb friction model. Parameters of the DRECE process adopted in the simulation are presented in Table 1. The material rheology was described on a base of the static
Fig. 1 Microstructure of the investigated steel in the initial state-a LM, b STEM; the material etched in the Marshall's reagent: $8 \mathrm{~g}$ of oxalic acid $+5 \mathrm{ml}$ of $\mathrm{H}_{2} \mathrm{SO}_{4}+100 \mathrm{ml}$ of $\left(\mathrm{H}_{2} \mathrm{O}+\mathrm{H}_{2} \mathrm{O}_{2} 30 \%\right)+1 \mathrm{ml}$ of $\mathrm{HF}$ (a)

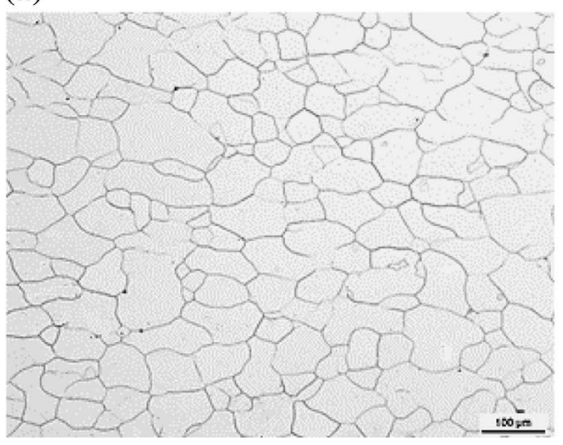

(b)

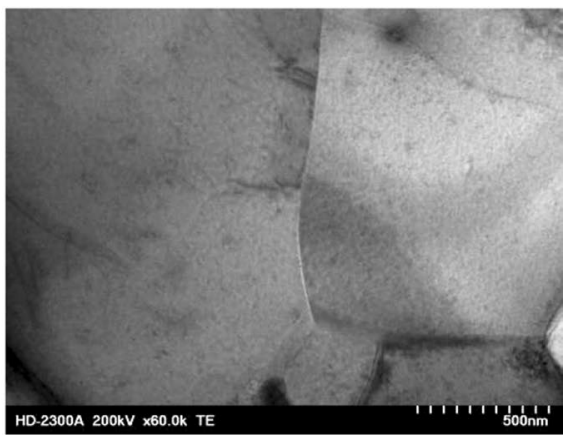


Fig. 2 The geometric models of the DRECE device and the steel strip used in the simulation case analysed

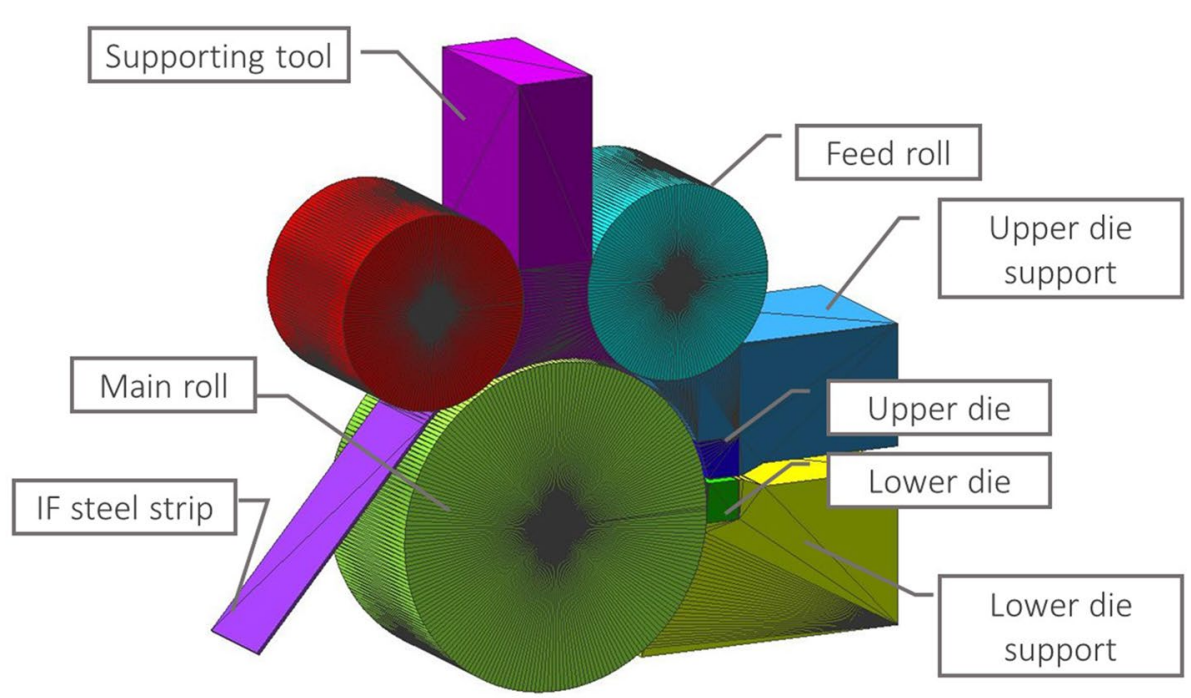

Table 1 Parameters of the DRECE process used in the numerical simulation

\begin{tabular}{lll}
\hline Parameter & Value & Unit \\
\hline The diameter of the main roll $D$ & 198 & $\mathrm{~mm}$ \\
The diameter of feed rolls $d$ & 118 & $\mathrm{~mm}$ \\
The rotational speed of the main roll $n$ & 1 & $\mathrm{rpm}$ \\
The rotational speed of the feed rolls $n_{1}$ & 1.6 & $\mathrm{rpm}$ \\
The linear speed of the strip $V$ & 10 & $\mathrm{~mm} / \mathrm{s}$ \\
The pressing force of the first feed roll $P_{1}$ & 11 & $\mathrm{kN}$ \\
The pressing force of the second feed roll $P_{2}$ & 37 & $\mathrm{kN}$ \\
The friction factor at the strip-rolls interfaces & 0.3 & - \\
The friction factor at the strip-remaining tools & 0.1 & - \\
interfaces & & \\
\hline
\end{tabular}

Fig. 3 The flow curve of the investigated steel at the initial state tensile test conducted for the investigated steel at the initial state (Fig. 3). The data range corresponding only to the uniform elongation range was used for the calculations. Due to the relatively small true strain obtained in this range (much smaller than in the DRECE process), coefficients of the Hollomon flow stress function was determined by the least-squares method. This allowed for extrapolation of the flow curve to higher true strain values (Fig. 3). For the true strain exceeding 0.1 the flow stress of investigated steel at the initial state is given by the formula:

$\sigma_{f}=475 \varepsilon^{0.23}$

where $\varepsilon$ denotes the true strain.

The mechanical properties and hardness of the steel strips were determined for the initial state and after each DRECE pass. The static tensile tests were conducted at the room temperature on ZWICK testing machine with a

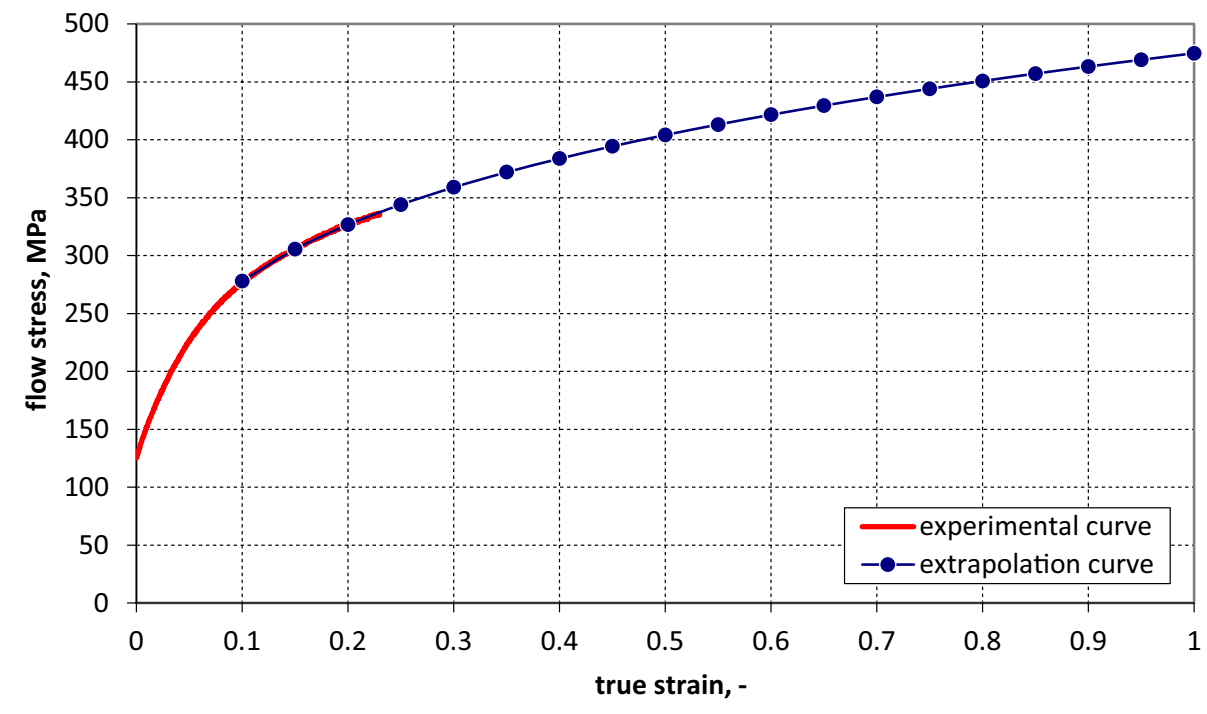


maximal force of $250 \mathrm{kN}$. Samples for the static tensile tests had the total length of $100 \mathrm{~mm}$, the gauge length of $30 \mathrm{~mm}$, the gauge width of $8 \mathrm{~mm}$ and the thickness of $2 \mathrm{~mm}$. The following properties were determined: the ultimate tensile strength UTS, the yield strength YS, the percent uniform elongation \% UE and the percent elongation \%EL. The hardness of strips was measured at a load of $1 \mathrm{~N}$ (HV0.1) with the ZWICK Roel ZHU hardness tester, on the polished longitudinal sections.

The fractographic observations were conducted using the scanning electron microscope Hitachi S-4200. The SEM and STEM observations were made also on the longitudinal sections. Additionally, the scanning transmission electron microscope (STEM) Hitachi HD-2300A was used for microstructure characterization.

\section{Results}

\subsection{The finite element simulation results}

The DRECE process progression determined by numerical modelling is shown in Fig. 4. The simulation was initiated at the moment when the strip was fed into the area between the main roll, the upper support and both backing rolls (Fig. 4a). After $4 \mathrm{~s}$ the strip head reached the inlet channel (Fig. 4b) and after subsequent $2 \mathrm{~s}$-the channel angle (Fig. 4c). Then the material was extruded through the angular channel (Fig. 4d-f). The simulation revealed that during the extrusion a characteristic folding of the strip took place in the gap between the second backing roll, the upper die support and the main roll. This coincides with the observations of processed strip surfaces with distinctly visible folding traces (Fig. 5). The probable explanation of this fact is that the pressure needed to fold the strip in
Fig. 4 Progression of the DRECE process determined by FEM

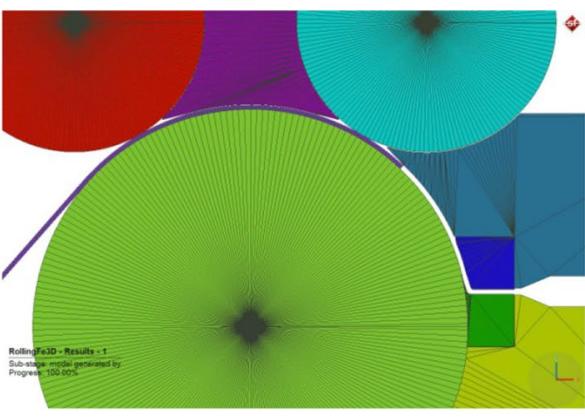

(a) start of simulation

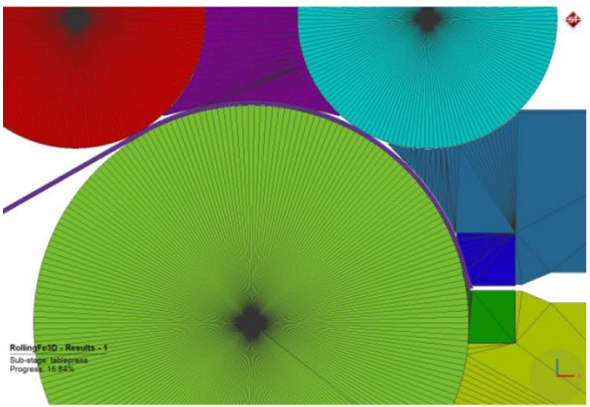

(c) ca. $6 \mathrm{~s}$ from the start

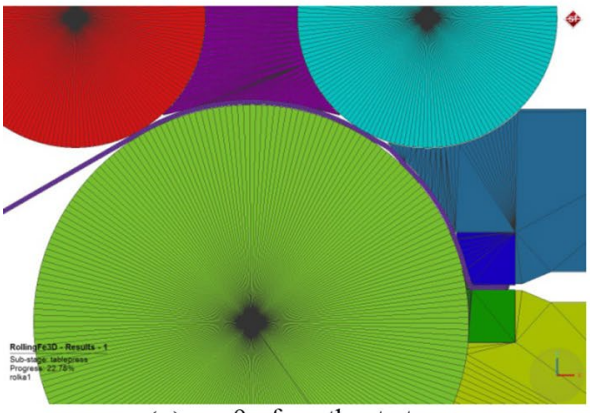

(e) ca. $9 \mathrm{~s}$ from the start

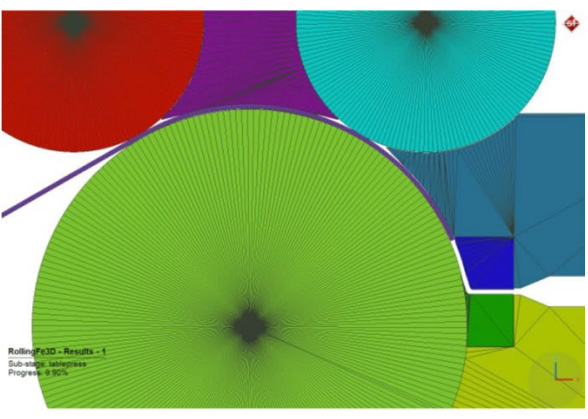

(b) ca. $4 \mathrm{~s}$ from the start

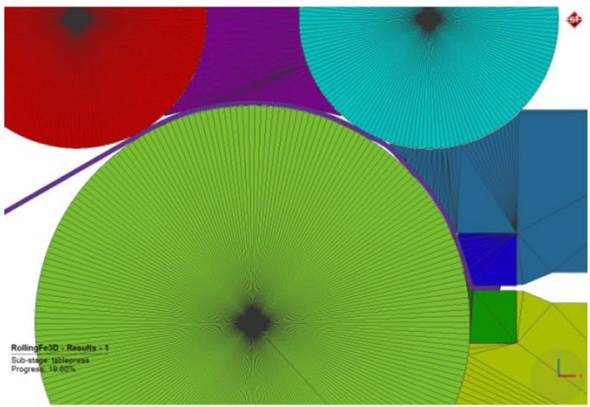

(d) ca. $8 \mathrm{~s}$ from the start

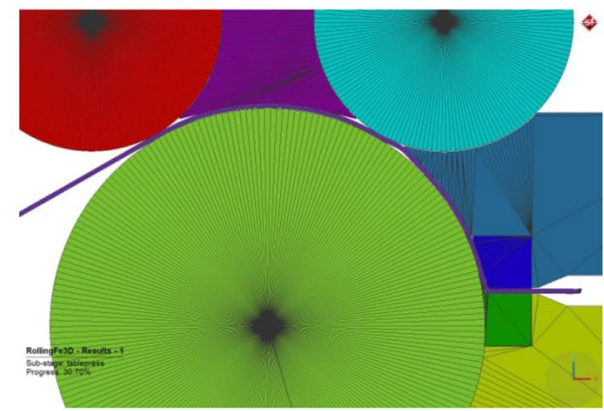

(f) ca. $12 \mathrm{~s}$ from the start 
Fig. 5 The evidence of the strip folding in the area just before entering into the dies: $\mathbf{a}$ the simulation result $\mathbf{b}$ the processed strip
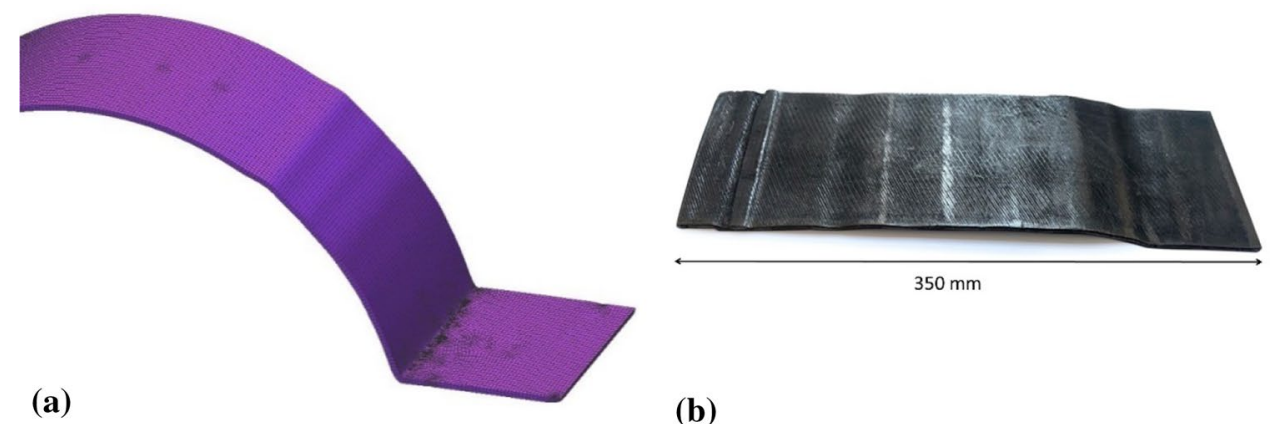

(b)
Fig. 6 The distribution of von Mises effective stress along the strip during the DRECE process

Fig. 7 The distribution of von Mises effective stress and the strip thickness measurement in the area of the upper die entrance
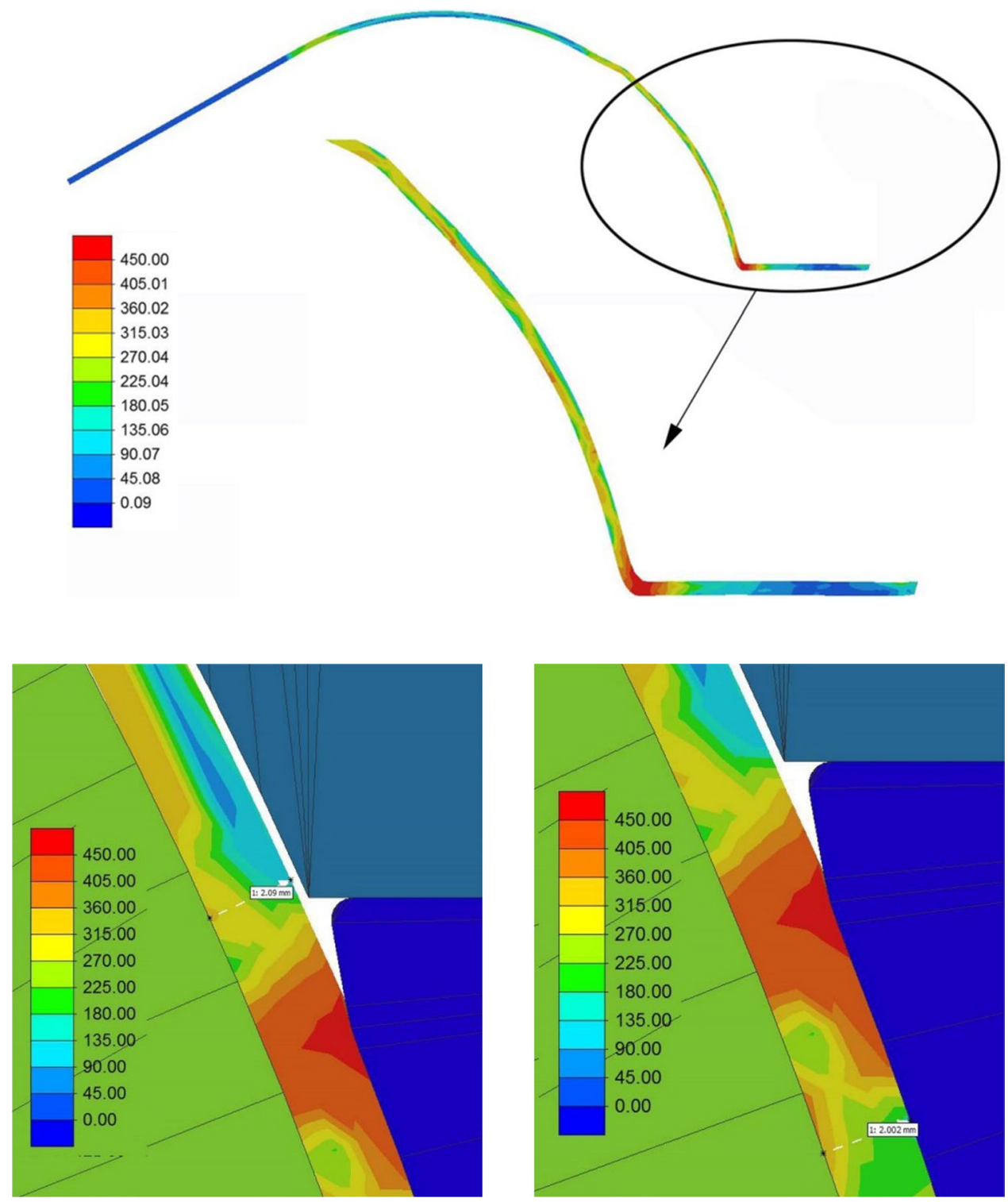

this gap is smaller than the pressure necessary to push the material through the angular channel. It can be concluded inter alia from the effective stress distribution along the strip that is presented in Fig. 6. Moreover, as a result of high longitudinal compressive stress in the channel between the upper die support and the main roll (where the gap is higher than $2 \mathrm{~mm}$ to avoid the unnecessary friction) the strip was subjected to upsetting, and thus its thickness slightly 
increased. Conducted measurements (Fig. 7) have indicated that the strip thickness was ca. $2.09 \mathrm{~mm}$ before entering the upper die. Next, due to the smaller, fixed gap between the main roll and the upper die, the strip thickness was reduced again to $2 \mathrm{~mm}$. The significant increase of the effective stress has been noticed in this area.

The revealed folding and upsetting phenomena caused an initial, unintended deformation of the material. The strain distribution presented in Fig. 8a indicates that the effective strain of ca. 0.2 was obtained in the strip yet before it entered the channel angle, where the intended deformation takes place. Moreover, it also shows that the strain distribution is not homogeneous. This heterogeneity can be observed both along the strip as well across its thickness. Apart from the strip head, the effective strain in the initial part of the strip (which was not subjected to folding and upsetting) is slightly lower than in the part of the strip located further (where folding and upsetting took place). However, the effective strain heterogeneity is more distinct across the strip thickness - the greatest effective strain (ca. 1.0) was obtained on the upper side of the strip, while on the lower side it was two times smaller. The maps of hardness distribution on these surfaces coincide with the observed strain heterogeneity (Fig. 8b). Such a strain distribution is typical for the processes of extrusion through an angular channel and has often been presented in the studies concerning, among others, the ECAP process.

\subsection{The mechanical properties and fracture behaviour}

The engineering stress-engineering strain diagram, collecting all the curves obtained in the static tensile tests, is presented in Fig. 9. The determined mechanical properties of the tested samples are listed in Table 2. Both the yield strength and the ultimate tensile strength of the steel increased significantly after the first DRECE pass and reached the values of $289 \mathrm{MPa}$ and $320 \mathrm{MPa}$, respectively. The material strengthened after every subsequent pass, however, much less intensively than in the first pass. After the seventh pass, the highest values of YS and UTS for the tested material were obtained: $318 \mathrm{MPa}$ and $338 \mathrm{MPa}$, respectively. In the initial state the investigated steel exhibits very good plastic properties; however, as the number of passes increases, there is a significant decrease in the ductility. The percent elongation drops systematically from $48 \%$ for the sample in the initial state to $10 \%$ for the sample after 7 th pass. The uniform elongation after subsequent passes drops rapidly already after the first DRECE pass and is about $1 \%$. The steel hardness increases considerably after the first pass in comparison to the initial material. After seven passes, it reaches the average value of $144 \mathrm{HVO} .1$. The obtained results confirm those presented in the paper [30] where the authors have analysed the effect of a severe plastic deformation (SPD) technique called equal-channel angular sheet extrusion (ECASE) on the properties of IF-steel sheets.

The static tensile test results are supported by the results of fractographic examinations presented in Fig. 10. The ductile fracture surface with characteristic small parabolic dimples formed by joining the microvessels has been obtained (a)

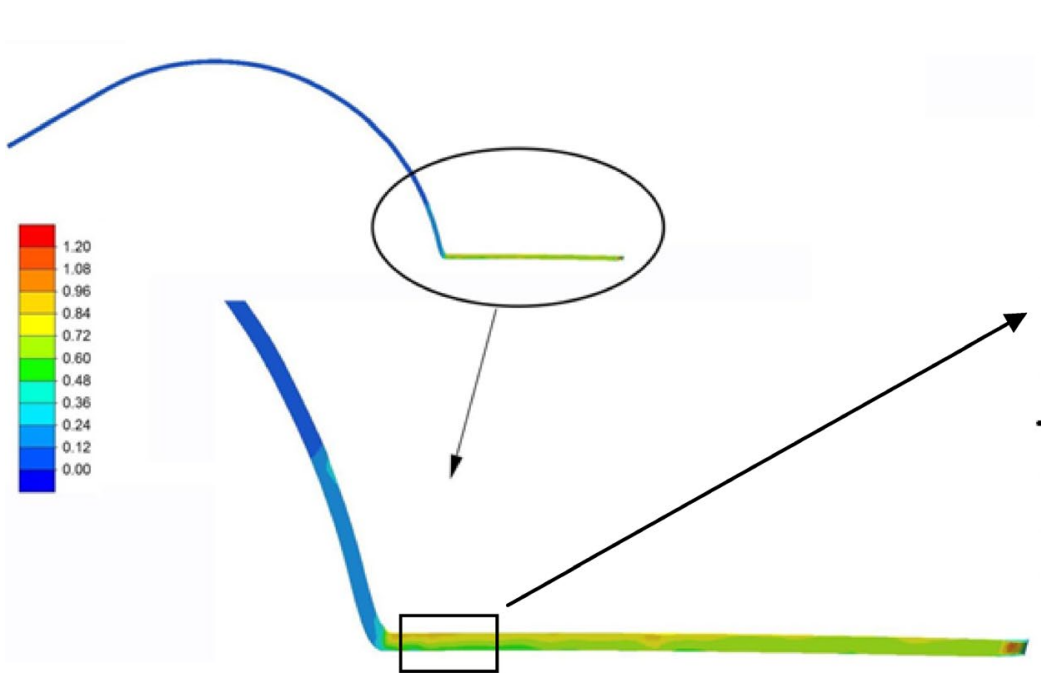

(b)

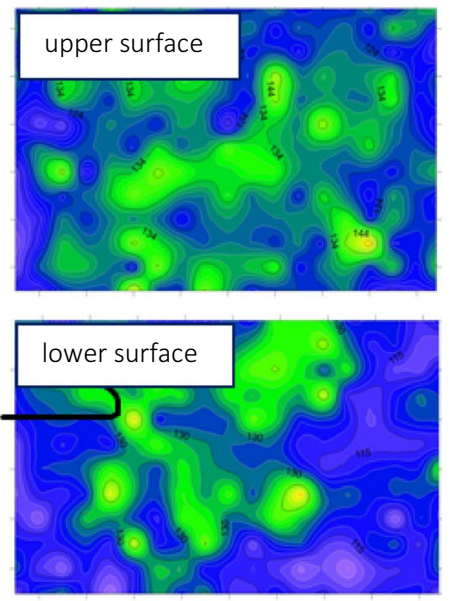

Fig. 8 The effective strain distribution (a) and the hardness distribution in the upper and lower surface (b) 
Fig. 9 Comparison of the engineering stress-engineering strain curves from static tensile tests obtained for the investigated steel in the initial state and after the selected DRECE passes

\begin{tabular}{llllll}
\hline Condition & YS, MPa & UTS, MPa & EL, $\%$ & UE, $\%$ & HV0.1 \\
\hline Initial state & $125 \pm 8$ & $268 \pm 6$ & $48 \pm 4$ & $24 \pm 2$ & $118 \pm 9$ \\
After 1 DRECE pass & $289 \pm 5$ & $320 \pm 4$ & $27 \pm 3$ & $1.0 \pm 0.2$ & $131 \pm 11$ \\
After 4 DRECE passes & $308 \pm 9$ & $328 \pm 6$ & $14 \pm 2$ & $1.0 \pm 0.4$ & $134 \pm 7$ \\
After 7 DRECE passes & $318 \pm 10$ & $338 \pm 5$ & $10 \pm 5$ & $1.1 \pm 0.2$ & $144 \pm 4$ \\
\hline
\end{tabular}

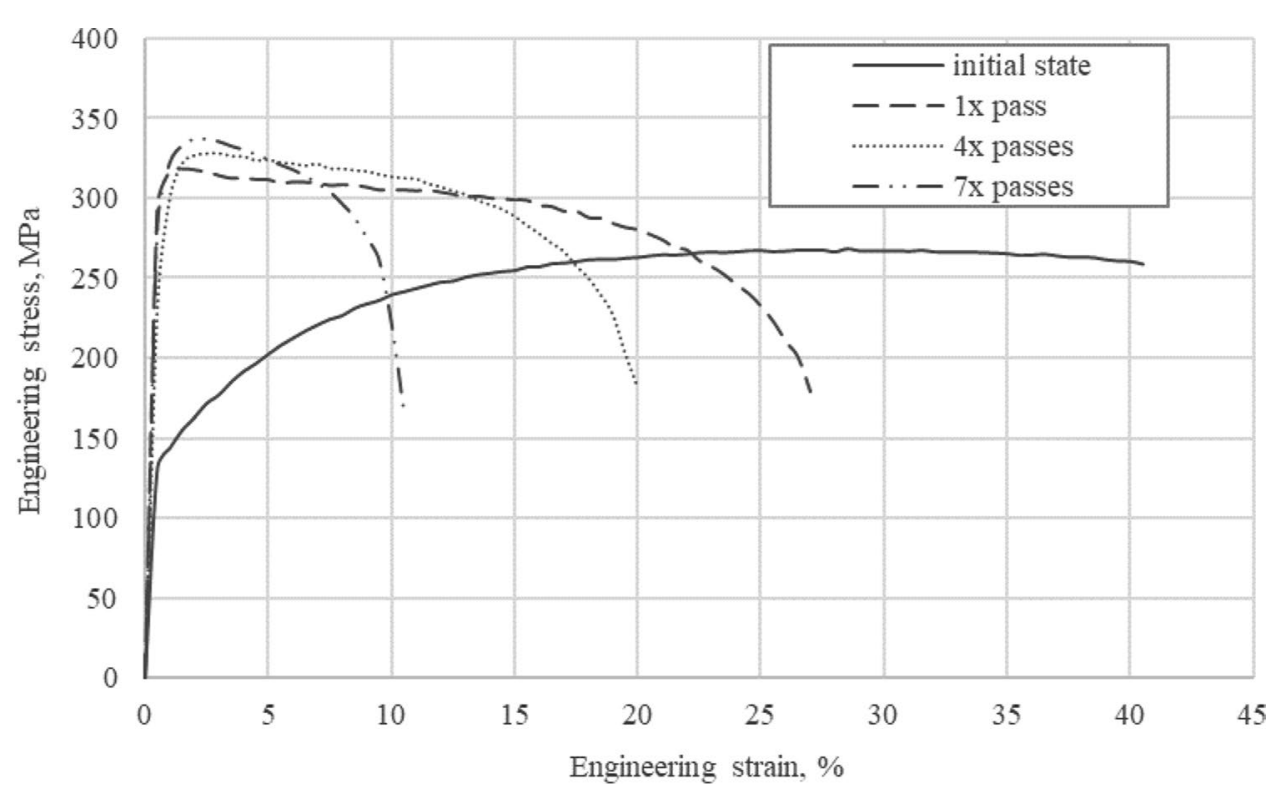

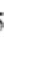

Table 2 Mechanical properties of the investigated steel in the initial state and after the DRECE process 
Fig. 10 Fracture surfaces of the static tensile test samples: $\mathbf{a}$ at the initial state, $\mathbf{b}$ after 1 DRECE pass $\mathbf{c}$ after 7 DRECE passes (a)
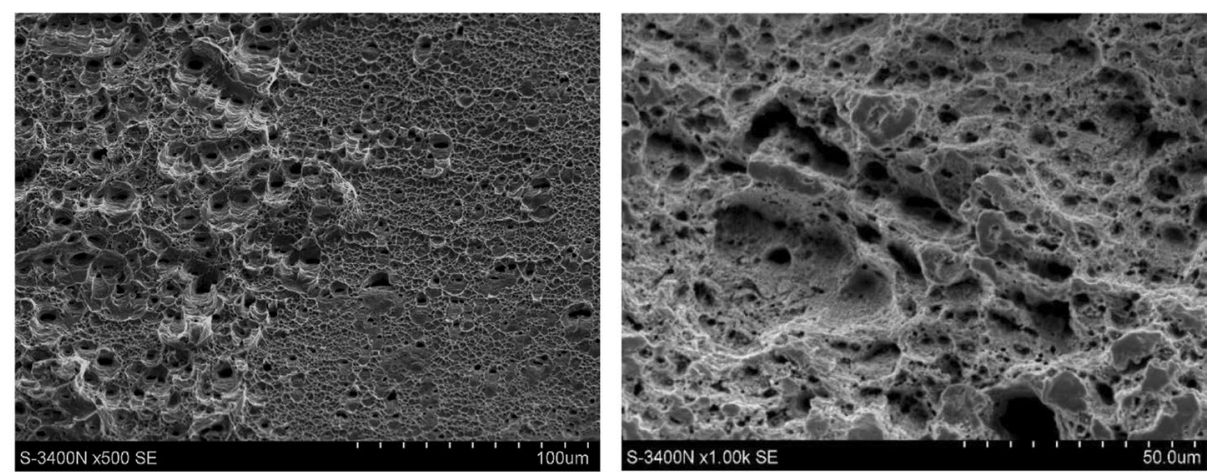

(b)
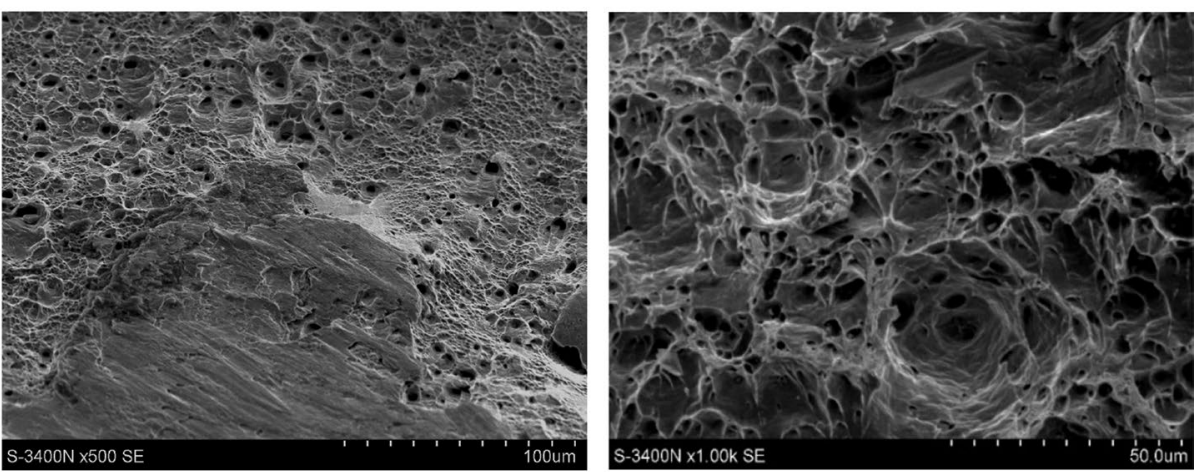

(c)

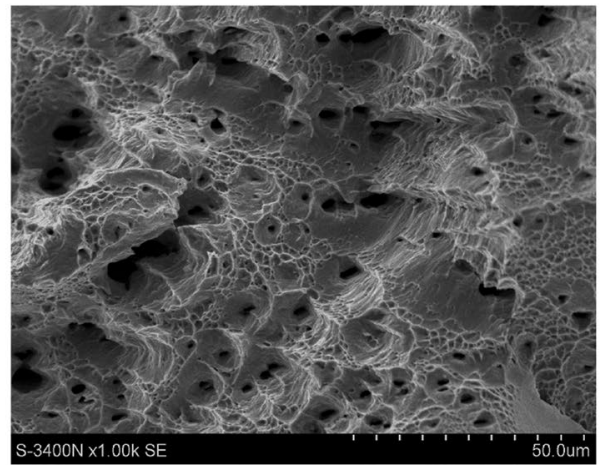

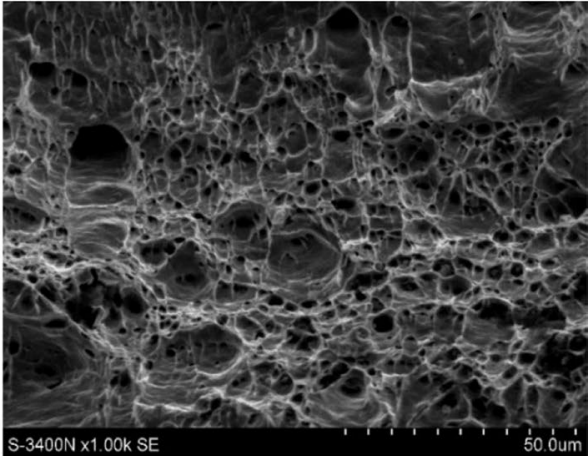

grain refinement. The surface share of grains/subgrains of the dimension of up to $1 \mu \mathrm{m}$ is $56 \%$. Visible fragments of high-angle boundaries belong mainly to original boundaries of grains (see Figs. 12 and 13).

\section{Conclusions}

The DRECE (dual rolls equal channel extrusion) process has been applied for processing of low-carbon ferritic steel strips. After subsequent DRECE passes, the microstructure and resulting mechanical properties of the strips have been investigated systematically. The main findings and conclusions of this study can be summarized as follows:

1. The low-carbon ferritic steel strips were successfully processed using the DRECE device.

2. 7 passes at room temperature were conducted.
3. The numerical simulation of the DRECE process allowed to analyse the material flow as well as the effective strain and stress distributions during process progression. Unintended folding and upsetting of the strip yet before its passing through the channel angle were revealed and discussed. These findings confirm nakedeye observations of strip surfaces after DRECE process. These device-specific issues cause initial deformation in a part of the strip and contribute to the strain heterogeneity.

4. A distinct strain heterogeneity across the strip thickness was indicated, which was confirmed by the results of microhardness distribution. To increase the strain homogeneity, it is recommended to rotate the strip upside down before each subsequent DRECE pass.

5. The strength of the DRECE-processed low-carbon ferritic steel strips increased with an increase in the number of passes. The most distinct material strengthening 
Fig. 11 STEM photographs of the investigated steel microstructure after: 1 DRECE pass (a, b), 3 DRECE passes (c, d), 7 DRECE passes $(\mathbf{e}, \mathbf{f})$,
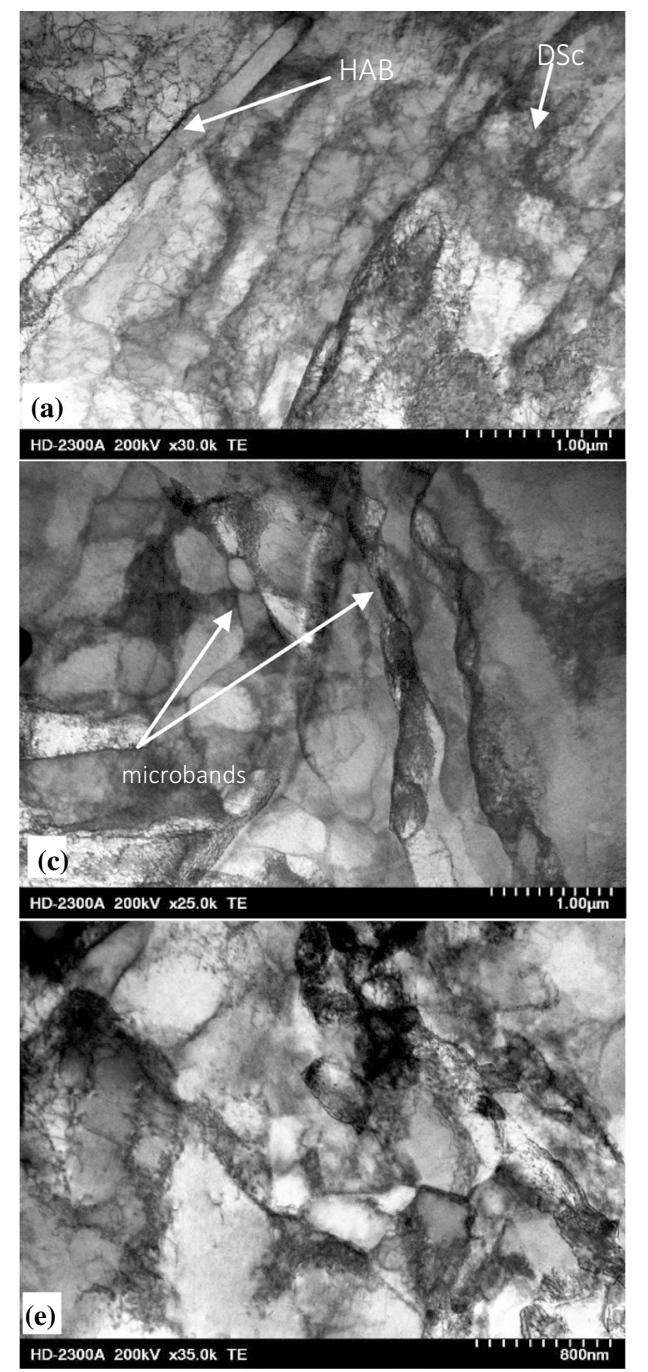

(a)

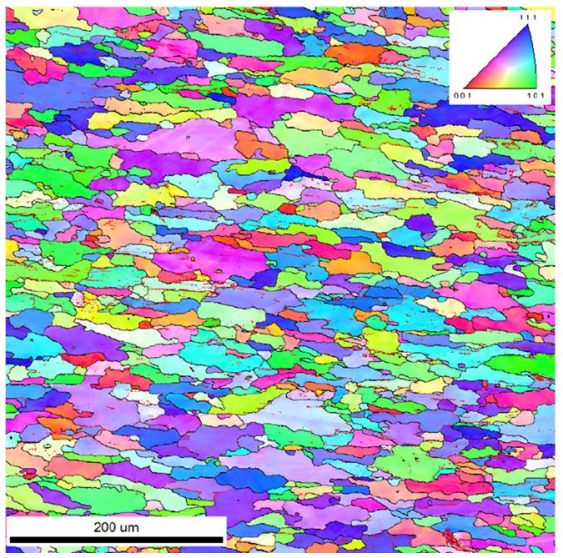

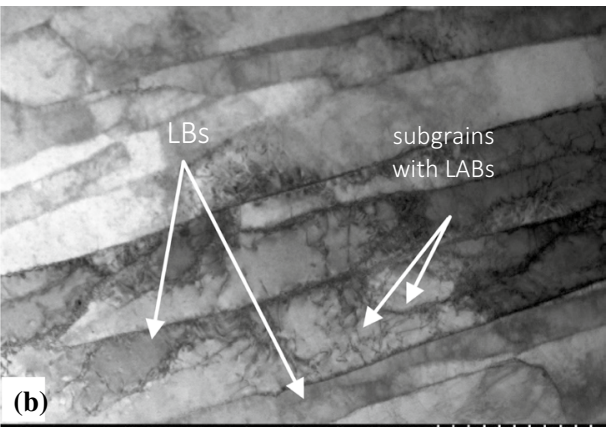
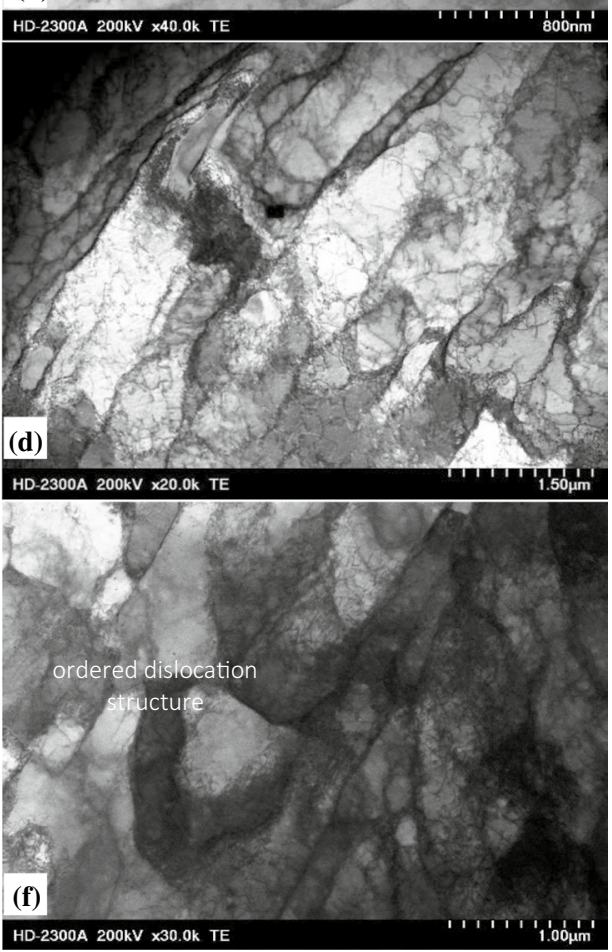

(b)

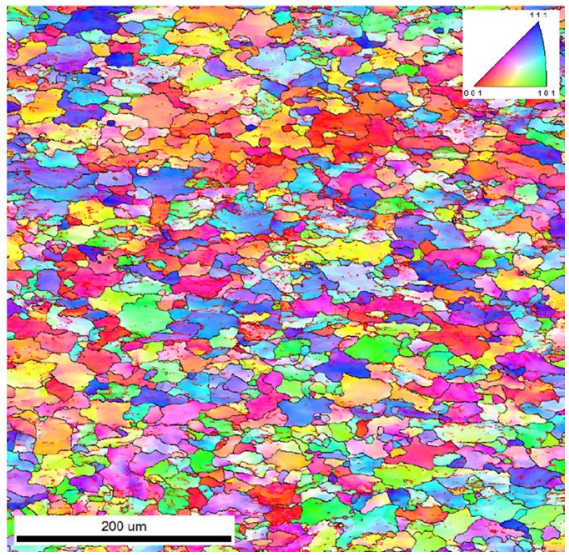

Fig. 12 EBSD maps of grain crystallographic orientation for the investigated steel after 1 DRECE pass (a) and 7 DRECE passes (b); high-angle boundaries are coloured black and low-angle boundaries are coloured red was obtained after the first pass. In the further passes, it was less intensive. After 7 DRECE passes the yield strength of $318 \mathrm{MPa}$ and the ultimate tensile strength of $338 \mathrm{MPa}$ were reached, which are significantly higher than the corresponding strength values characterizing the material at the initial state (125 and $268 \mathrm{MPa}$, respectively). However, the elongation to failure considerably decreased with the number of passes. After 7 

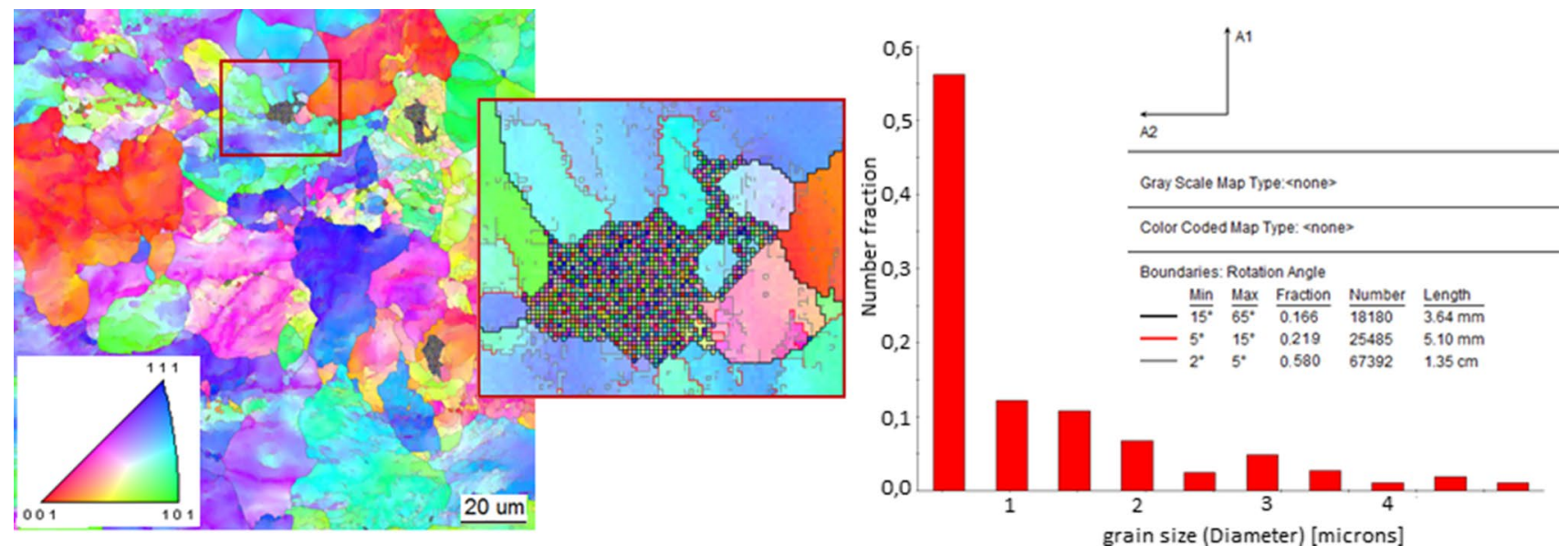

Fig. 13 Map of grain crystallographic orientation, statistics on intergrain boundaries and grain size distribution for the investigated steel after 7 DRECE passes

passes, it decreased down to $10 \%$ from $48 \%$ in the initial state.

6. The increase in strength after the DRECE process is attributed to the fact that such a deformation method produces refined microstructure with a relatively high density of dislocations. The observed decrease in the ductility is typical for ultrafine-grained materials and is associated with strong localization of plastic deformation in samples with grain sizes below $0.5 \mu \mathrm{m}$.

7. The DRECE process resulted in the grain refinement but the obtained microstructure is not homogeneous. The microstructure is constantly evolving. Bands mainly with low-angle grain boundaries are visible in the dislocation cells, as well as the intense microband formation inside the grains.

8. Generally the ductile fracture behaviour of IF steel subjected to the DRECE process with a small semi-brittle zones was revealed in the fractographic studies.

Acknowledgements The financial support of the National Science Center, Poland and the Ministry of Science and Higher Education, Poland is gratefully acknowledged.

Funding This study was funded by the National Science Center, Poland (Grant No. 2018/31/N/ST8/03134) and the Ministry of Science and Higher Education, Poland (Grant No. BK-260/RM3/2020).

\section{Compliance with ethical standards}

Conflict of interest All Authors declared that they have no conflict of interest. The authors have no financial or proprietary interests in any material discussed in this article.

Ethical approval This article does not contain any studies with human participants or animals performed by any of the authors.
Informed consent Informed consent was obtained from all individual participants included in the study.

Open Access This article is licensed under a Creative Commons Attribution 4.0 International License, which permits use, sharing, adaptation, distribution and reproduction in any medium or format, as long as you give appropriate credit to the original author(s) and the source, provide a link to the Creative Commons licence, and indicate if changes were made. The images or other third party material in this article are included in the article's Creative Commons licence, unless indicated otherwise in a credit line to the material. If material is not included in the article's Creative Commons licence and your intended use is not permitted by statutory regulation or exceeds the permitted use, you will need to obtain permission directly from the copyright holder. To view a copy of this licence, visit http://creativecommons.org/licenses/by/4.0/.

\section{References}

1. Gleiter H. Nanostructured materials: basic concept and microstructure. Acta Mater. 2000;48:1-29.

2. Valiev RZ. Developing of SPD processing bulk nanostructured materials. Met Mater. 2001;7:413-20.

3. Zhu YT, Langdon TG. The fundamentals of nanostructured materials processed by severe plastic deformation. JOM. 2004;58:58-63.

4. Alexander DJ. New methods for severe plastic deformation processing. J Mater Eng Perform. 2007;16:360-74.

5. Song R, Ponge D, Raabe D, Speer JG, Matlock DK. Overview of processing, microstructural and mechanical properties of ultrafine grained bcc steels. Mater Sci Eng A. 2006;441:1-17.

6. Xu C, Furukawa M, Horita Z, Langdon TG. The evolution of homogeneity and grain refinement during equal—channel angular pressing: a model for grain refinement in ECAP. Mater Sci Eng A. 2005;398:66-76.

7. Degtyarev MV. Influence of the relaxation processes on the structure formation in pure metals and alloys under high-pressure torsion. Acta Mater. 2007;55:6039-50. 
8. Jiang H, Zhu Y, Butt D, Alexandrov IV. Microstructural evolution, microhardness and thermal stability of HPT-processed $\mathrm{Cu}$. Mater Sci Eng A. 2000;290:128-38.

9. Tsuji N, Ueji R, Minamino Y. Nanoscale crystallographic analysis of ultrafine grained IF steel fabricated by ARB process. Scr Mater. 2002;47:69-76.

10. Zherebtsov S, Salischchev G, Łojkowski W. Strengthening of a Ti-6Al-4V titanium alloy by means of hydrostatic extrusion and other methods. Mater Sci Eng A. 2009;515:43-8.

11. Bochniak W, Korbel A. Type forming: forging of metals under complex conditions of the process. J Mater Process Technol. 2003;134:120-34.

12. Sabbaghianrad S, Langdon TG. A critical evaluation of the processing of an aluminium 7075 alloy using a combination of ECAP and HPT. Mater Sci Eng A. 2013;596:126-35.

13. Wongsa-Ngam J, Wen H, Langdon TG. Microstructural evolution in a $\mathrm{Cu}-\mathrm{Zr}$ alloy processes by a combination of ECAP and HPT. Mater Sci Eng A. 2012;579:105-15.

14. Stepanov ND, Kuznetsov AV, Salishchev GA, Raab GI, Valiev RZ. Effect of cold rolling on microstructure and mechanical properties of copper subjected to ECAP with various numbers of passes. Mater Sci Eng A. 2012;554:105-15.

15. Rodak K, Urbańczyk-Gucwa A, Jabłońska MB. Microstructure and properties of $\mathrm{CuCr}_{06}$ and $\mathrm{CuFe}_{2}$ alloys after rolling with the cyclic movement of rolls. Arch Civil Mech Eng. 2018;18:500-7.

16. Rusz S, Cizek L, Michenka V, Dutkiewicz V, Salajka J, Hilser M, Tylsar S, Kedron J, Klos M. New type of device for achievement of grain refinement in metal strip. Arch Mater Sci Eng. 2014;69:38-44.

17. Hilser O, Salajka M, Rusz S. Study of mechanical properties of steel and selected types of non-ferrous alloys after application of the DRECE process. In: Proceedings 7th International Conference on Nanomaterials - Research \& Application - Nanocon 2015. Brno, Czech Republic. https://www.confer.cz/nanocon/2015/574study-of-mechanical-properties-of-steel-and-selected-types -of-non-ferrous-alloys-after-application-of-the-drece-process. Accessed 10 Sep 2020.

18. Kowalczyk K, Jabłońska M, Rusz S, Bednarczyk I. Influence of the DRECE process of severe plastic deformation on the mechanical properties of the ultra-low carbon interstitial free steel. Arch Metall Mater. 2018;63:1957-61.

19. Rusz S, Hilser O, Ochodek V, Cizek L, Kraus M, Mares V, Grajcar A, Svec K. Effect of severe plastic deformation on mechanical and fatigue behaviour of medium-C sheet steel. J Min Metall Sect B. 2020. https://doi.org/10.2298/JMMB190910008R.
20. Suo T, Li Y, Guo Y, Liu Y. The simulation of deformation distribution during ECAP using 3D finite element method. Mater Sci Eng A. 2006;432:269-74.

21. Mani B, Jahedi M, Paydar M. A modification on ECAP process by incorporating torsion deformation. Mater Sci Eng A. 2011;528:4159-65.

22. Zhao WJ, Ding H, Ren YP, Hao SM, Wang J, Wang JT. Finite element simulation of deformation behavior of pure aluminum during equal channel angular pressing. Mater Sci Eng A. 2005;411:348-52.

23. Rosochowski A, Olejnik L. Finite element simulation of severe plastic deformation processes. J Mater Des Appl. 2007;221:311-24.

24. Rosochowski A, Olejnik L. Numerical and physical modelling of plastic deformation in 2-turn equal channel angular extrusion. $\mathrm{J}$ Mater Process Technol. 2002;126:309-16.

25. Bourke L, Beyerlein M, Alexander J, Clausen DJ. Finite element analysis of the plastic deformation zone and working load in equal channel angular extrusion. Mater Sci Eng A. 2004;382:17-236.

26. Luis-Perez CJ, Luri-Irigoyen R, Gastón-Ochoa R. Finite element modelling of an Al-Mn alloy by equal channel angular extrusion (ECAE). J Mater Process Technol. 2004;154:846-52.

27. Dumoulin S, Roven HJ, Werenskiold JC, Valberg HS. Finite element modeling of equal channel angular pressing: effect of material properties, friction and die geometry. Mater Sci Eng A. 2005;410:248-51.

28. Baik SC, Estrin Y, Kim HS, Hellmig RJ. Dislocation density-based modeling of deformation behavior of aluminium under equal channel angular pressing. Mater Sci Eng A. 2003;351:86-97.

29. Rusz S, Salajka M, Hilser O, Dutkiewicz J, Boruta J, Svec J. Influence of the forming tool parameters on the grain refinement of brass by SPD process. Metal Form. 2016;27(4):301-14.

30. Saray O, Purcek G, Karaman I, Neindorf T, Maier HJ. Equalchannel angular sheet extrusion of interstitial-free (IF) steel: microstructural evolution and mechanical properties. Mater Sci Eng A. 2011;528:6573-83.

Publisher's Note Springer Nature remains neutral with regard to jurisdictional claims in published maps and institutional affiliations. 